\title{
Discordance of Epidermal Growth Factor Receptor Mutation between Brain Metastasis and Primary Non-Small Cell Lung Cancer
}

\author{
Kyung-Min Kim*, Seung-Hoon Lee ${ }^{2 \star}$, Seung-Min Kim², Nae-Yu Kim³, Ho-Shin Gwak4, Sang-Hoon Shin ${ }^{5}$, Ji-Woong Kwon ${ }^{5}$, Heon Yoo \\ 'Department of Neurosurgery, Seoul National University Hospital, Seoul, Korea \\ Departments of ${ }^{2}$ Neurosurgery, ${ }^{3}$ Internal Medicine, Eulji University Hospital, Daejeon, Korea \\ ${ }^{4}$ Department of Cancer Control, National Cancer Center Hospital, Goyang, Korea \\ ${ }^{5}$ Neuro-Oncology Clinic, National Cancer Center Hospital, Goyang, Korea
}

\author{
Received September 20, 2019 \\ Revised September 27, 2019 \\ Accepted October 8, 2019 \\ Correspondence \\ Heon Yoo \\ Neuro-Oncology Clinic, \\ National Cancer Center Hospital, \\ 323 Ilsan-ro, Ilsandong-gu, \\ Goyang 10408, Korea \\ Tel: $+82-31-920-1666$ \\ Fax: +82-31-920-2798 \\ E-mail: heonyoo@ncc.re.kr \\ *These authors contributed equally
} to this work.
Background The aim of this study was to compare epidermal growth factor receptor (EGFR) mutations between non-small cell lung cancer (NSCLC) and corresponding brain metastases (BMs) in Korea society.

Methods From 2011 to 2016, a total of 74 patients underwent surgical resection of a metastatic brain tumor from NSCLC. Among them, we performed retrospective analysis for 46 patients who underwent EGFR sequencing of primary NSCLC tissues.

Results Among these 46 cases, 18 (39.1\%) cases showed EGFR mutation in primary lung cancer. Detected mutation sites were exon 19 (8 cases), exon 21 (6 cases), exon 18 (1 cases), and multiple mutations ( 3 cases). In 18 cases of BM, EGFR mutation studies were done. Among them, 8 (25.6\%) cases showed mutation on exon 19 (5 cases) or exon 21 (3 cases). To compare EGFR mutation status between primary lung cancer and BM, 18 paired tissues from both NSCLC and matched BM were collected. Four (22.5\%) patients were discordant for the status of EGFR between primary and metastatic sites.

Conclusion EGFR mutations were significantly discordant between primary tumors and corresponding metastases in a significant portion of NSCLC. In treatment of BM of EGFR mutant metastatic NSCLC, due to possibility of discordance, pathologic confirming through brain biopsy is recommended.

Key Words Metastasis; Lung cancer; Mutation; Epidermal growth factor receptor.

\section{INTRODUCTION}

Lung cancer is major cause of cancer death. Non-small cell lung cancer (NSCLC) accounts for about $80 \%$ of all lung cancers [1]. Traditionally, surgical resection with or without adjuvant chemotherapy is major treatment choice for lung cancer. However, due to poor therapeutic response and high mortality rate, research has focused on understanding molecular mechanism of cancer [1]. Due to development of molecular biology, molecular targeted agent such as epidermal growth

This is an Open Access article distributed under the terms of the Creative Commons Attribution Non-Commercial License (https://creativecommons.org/licenses/by-nc/4.0) which permits unrestricted non-commercial use, distribution, and reproduction in any medium, provided the original work is properly cited.

Copyright $\odot 2019$ The Korean Brain Tumor Society, The Korean Society for NeuroOncology, and The Korean Society for Pediatric Neuro-Oncology factor receptor (EGFR) tyrosine kinase inhibitors (TKI) is used significantly in the treatment of NSCLC. Some patients have shown dramatic response to TKI $[2,3]$. Patients with EGFR mutation have longer median progression free survival than those with wild-type EGFR disease (15.2 months versus 4.4 months, $p<0.05$ ) [4].

For patients with brain metastasis (BM), prognosis remains poor, with a median survival time of 4.5-6.0 months despite standard treatment of whole-brain radiation therapy (WBRT) [5-9]. About 50\% patients of NSCLC have BM. However, characteristics of BM are not well established yet [9].

In Korea society, EGFR mutation rate in NSCLC has been reported to be about $48.6 \%$ to $60 \%$ in BM [2]. Patients who receive an EGFR TKI therapy after diagnosis of BM are known to survive longer than those who do not [9], suggest- 
ing that TKI therapy might be also effective in metastatic brain lesion. However, TKI therapy in BM did not always reveal good treatment results. This might be due to different EGFR mutational status between BM and primary NSCLC. Thus, the objective of this study was to determine EGFR mutational status in BM and primary NSCLC and compare the discordance rate of paired EGFR mutation status. This is the first report to analyze the discordance rate between metastatic brain tumors and NSCLC in Korea society.

\section{MATERIALS AND METHODS}

Records of patients who underwent craniotomy for metastatic brain tumors arising from NSCLC at the Neuro-Oncology Clinic of the National Cancer Center of Korea between 2011 and 2016 were retrospectively reviewed. A total of 74 patients underwent surgical resection of a metastatic brain tumor from NSCLC. Among them, retrospective clinical review was performed for 46 patients who underwent EGFR sequencing analysis for primary NSCLC tissues or metastatic brain tissue. Status of EGFR mutations was determined by using peptide nucleic acid mediated real-time PCR clamping method. Pathologic data were collected from electronic medical records, including patient demographics, histological type, grade, tumor stage, and biomarker status.

We compared the EGFR mutation frequencies in both primary lung cancer and metastatic brain lesion and analyzed the mutational change of metastatic brain tumor. Based on the mutational change, we classified change in preexisting mutation as partial change, newly developed mutation as positive conversion, absence of mutation as negative conversion, respectively.

\section{RESULTS}

A total of 46 patients (28 males and 18 females) were included in this study. Their mean age was 62.2 (range, 36-83) years. Among these 46 cases, 18 (39.1\%) cases showed EGFR mutation in primary lung cancer. Detected mutation sites were exon 19 (8 cases), exon 21 (6 cases), exon 18 ( 1 cases), and multiple mutations ( 3 cases) (Table 1). About $61.1 \%$ (11/18) of female patients and 25\% (7/28) of male patients showed EGFR mutation. All female patients were never smokers. About $66.7 \%$ of male non-smokers showed EGFR mutation. In 18 cases of BM, EGFR mutation studies were done. Among them, 8 (25.6\%) cases showed mutation on exon 19 ( 5 cases) or exon 21 ( 3 cases). To compare EGFR mutation status between primary lung cancer and BM, 18 paired tissues from both NSCLC and matched BM were collected (Table 2). Four (22.5\%) patients were discordant for the status
Table 1. Result of EGFR mutation analysis: comparison between 46 patients who underwent EGFR sequencing

\begin{tabular}{lcc}
\hline \multicolumn{1}{c}{ EGFR status } & Primary NSCLC & Brain metastasis \\
\hline Wild & $28(61 \%)$ & $10(56 \%)$ \\
Mutated & $18(39 \%)$ & $8(44 \%)$ \\
Exon 18 & 1 & 0 \\
Exon 19 & 8 & 5 \\
Exon 21 & 6 & 3 \\
Exon $18+20$ & 1 & 0 \\
Exon $19+20$ & 1 & 0 \\
Exon 20+21 & 1 & 0 \\
N/A & 0 & 28 \\
Total & 46 & 46 \\
\hline
\end{tabular}

EGFR, epidermal growth factor receptor; NSCLC, non-small cell lung cancer

Table 2. Result of EGFR mutation analysis: comparison of paired 18 cases

\begin{tabular}{lcc}
\hline \multicolumn{1}{c}{ EGFR status } & Primary NSCLC & Brain metastasis \\
\hline Wild & $10(56 \%)$ & $10(56 \%)$ \\
Mutated & $8(44 \%)$ & $8(44 \%)$ \\
Exon 19 & 3 & 5 \\
Exon 21 & 3 & 3 \\
Exon $18+20$ & 1 & 0 \\
Exon $19+20$ & 1 & 0 \\
Total & 18 & 18 \\
\hline
\end{tabular}

EGFR, epidermal growth factor receptor; NSCLC, non-small cell lung cancer

of EGFR between primary and metastatic sites. There were two partial changes, positive conversion and negative conversion were one case each (Table 3).

\section{DISCUSSION}

Molecular targeted agents are becoming important treatment choice for cancer because they can lead to good prognosis. Several studies have shown that patients with EGFR mutations have better response to EGFR TKI therapy than those without such mutations [10,11]. In a prior study, Gow et al. [12] have retrospectively analyzed 63 NSCLC patients with BM who are treated with WBRT and found that 46 patients who have EGFR mutation have a median survival of 17.3 months while wild-type patients only have a median survival of 6.6 months [12]. A recent study has revealed that patients with EGFR-mutant metastatic lung adenocarcinoma have longer overall survival than wild type patients (30.9 months versus 12.1 months, $p<0.05$ ) [13]. Therefore, it is important to identify EGFR mutation status of metastatic lesion for anticipating prognosis. However, previous studies have shown that mutational status of metastatic lesion does not al- 
Table 3. Summarized results of paired 18 cases of EGFR mutation status

\begin{tabular}{|c|c|c|c|c|c|}
\hline Sex/Age & Synchr/Metachr & TKI & Lung cancer EGFR mutation & Brain metastasis EGFR mutation & Cordance \\
\hline $\mathrm{F} / 52$ & Meta & & - & - & Same \\
\hline $\mathrm{M} / 61$ & Synch & & - & - & Same \\
\hline $\mathrm{F} / 36$ & Meta & & - & - & Same \\
\hline $\mathrm{F} / 67$ & Meta & Iressa $^{\circledR}$ & Exon 21 & Exon 21 & Same \\
\hline $\mathrm{F} / 55$ & Meta & Iressa $^{\circledR}$ & Exon 19, 20 & Exon 19 & Partial change \\
\hline $\mathrm{F} / 65$ & Synch & Iressa $^{\circledR}$ & Exon 18,20 & Exon 21 & Partial change \\
\hline $\mathrm{M} / 72$ & Synch & & - & - & Same \\
\hline $\mathrm{M} / 63$ & Meta & & - & - & Same \\
\hline $\mathrm{M} / 46$ & Synch & Iressa $^{\circledR}$ & Exon 21 & Exon 21 & Same \\
\hline $\mathrm{M} / 68$ & Meta & Iressa $^{\circledR}$ & - & Exon 19 & Positive conversion \\
\hline $\mathrm{M} / 73$ & Meta & & - & - & Same \\
\hline $\mathrm{M} / 72$ & Meta & & - & - & Same \\
\hline $\mathrm{F} / 50$ & Synch & Tarceva $^{\circledR}$ & Exon 19 & Exon 19 & Same \\
\hline $\mathrm{M} / 63$ & Meta & Tarceva $^{(B)}$ & Exon 21 & - & Negative conversion \\
\hline $\mathrm{M} / 62$ & Meta & & - & - & Same \\
\hline $\mathrm{M} / 57$ & Synch & Tarceva $^{\circledR}$ & Exon 19 & Exon 19 & Same \\
\hline $\mathrm{M} / 59$ & Synch & & - & - & Same \\
\hline $\mathrm{M} / 61$ & Meta & & Exone 19 & Exon 19 & Same \\
\hline
\end{tabular}

EGFR, epidermal growth factor receptor; Synchr, synchronous metastasis; Metachr, metachronous metastasis; TKI, tyrosine kinase inhibitor; Iressa $^{\circledR}$, gefitinib; Tarceva ${ }^{\circledR}$, erlotinib

ways coincide with primary site. Through the literature review, discordance rate between primary tumor and corresponding metastasis is about $16.2 \%$ or $30 \%$ by immunohistochemistry analysis $[9,14]$. Many studies have revealed heterogeneity of cancer cells and different metastasis site [15-18]. In many studies conducted in other countries, mean discordance rate of EGFR mutation status between primary NSCLC and BM is 20\% (Table 4). Masumoto et al. [19] have analyzed 21 metastatic brain tumor tissues from 19 patients treated for lung cancers from 1986 to 2001. They found that all 6 cases with EGFR mutations in their metastatic brain tissues had the same mutational status in the corresponding primary lung cancers. In another study, Rau et al. [1] have analyzed 49 paired tissues with both primary adenocarcinoma of lung and metastatic brain lesion. Their results revealed a discordance rate of $26.5 \%$ between primary lung cancer and BM. In our case, in Korea, the discordant rate between primary NSCLC and metastatic brain lesion was $22.5 \%$, similar to that in the previous study [1]. It is known that EGFR mutations in lung cancer occur more frequently in East Asian patients than in Caucasian patients [19]. Therefore, we anticipated that the discordance rate of EGFR mutations would be higher in Asian patients. However, our study revealed that the discordance rate was not higher in Asian patients.

In univariate analysis, EGFR mutation has been found more frequently in female and never smokers [20]. In our study, female accounted for $61.1 \%$. All female patients were never smokers.
Table 4. Mean discordance rate of EGFR mutation status between primary NSCLS and BM in other studies

\begin{tabular}{lccc}
\hline \multicolumn{1}{c}{ Study } & $\begin{array}{c}\text { Matched } \\
\text { cases }\end{array}$ & $\begin{array}{c}\text { EGFR mutation } \\
\text { in BM, } \mathrm{n}(\%)\end{array}$ & $\begin{array}{c}\text { Discordance } \\
\text { rate }(\%)\end{array}$ \\
\hline Matsumoto et al. [19] & 8 & $6(75.0)$ & $0.0(0)$ \\
Kalikaki et al. [21] & 3 & $1(33.3)$ & $66.7(2$ cases $)$ \\
Gow et al. [3] & 25 & $11(44.0)$ & $16.0(4$ cases $)$ \\
Han et al. [2] & 5 & $3(60.0)$ & $20.0(1$ case $)$ \\
Luo et al. [22] & 15 & $8(53.3)$ & $6.7(1$ case $)$ \\
Rau et al. [1] & 49 & $30(61.2)$ & $26.5(13$ cases $)$ \\
Total & 105 & $59(56.1)$ & $20.0(21$ cases $)$ \\
\hline
\end{tabular}

EGFR, epidermal growth factor receptor; NSCLC, non-small cell lung cancer; BM, brain metastasis

This study has some limitations. First, we used retrospective methods that might have selection bias. Biopsy and molecular analysis of primary site and metastatic lesion were not performed at the same time. Moreover, subjects of this study were patients who underwent craniotomy. Surgeons usually recommend this surgery only for patients with favorable prognostic factors. Second, the total number of patients was small. Although treatment choice for BM was WBRT, many lung cancer patients were unsuitable for surgery. Thus, interpretation of our results should be done with these considerations.

For effective systemic therapy, molecular diagnosis of metastatic lesion is recommended. However, biopsy of brain metastatic lesion is not always performed due to limited access to metastatic lesion. Our results suggest that discordant 
rate between primary NSCLC and metastatic brain lesion is significant. Therefore, if EGFR-mutant NSCLC patients show no response to optimal treatment, we strongly recommend biopsy of metastatic brain lesion.

To the best of our knowledge, this is the first report to analyze a considerable number of metastatic brain tumors of lung adenocarcinoma for EGFR mutations and compare the discordance rate in South Korea.

\section{Conflicts of Interest}

The authors have no potential conflicts of interest.

\section{Acknowledgments}

This research was supported by National Cancer Center 1910110-1.

\section{REFERENCES}

1. Rau KM, Chen HK, Shiu LY, et al. Discordance of mutation statuses of epidermal growth factor receptor and K-ras between primary adenocarcinoma of lung and brain metastasis. Int J Mol Sci 2016;17:524.

2. Han HS, Eom DW, Kim JH, et al. EGFR mutation status in primary lung adenocarcinomas and corresponding metastatic lesions: discordance in pleural metastases. Clin Lung Cancer 2011;12:380-6.

3. Gow CH, Chang YL, Hsu YC, et al. Comparison of epidermal growth factor receptor mutations between primary and corresponding metastatic tumors in tyrosine kinase inhibitor-naive non-small-cell lung cancer. Ann Oncol 2009;20:696-702.

4. Wu YL, Zhou C, Cheng Y, et al. Erlotinib as second-line treatment in patients with advanced non-small-cell lung cancer and asymptomatic brain metastases: a phase II study (CTONG-0803). Ann Oncol 2013;24:993-9.

5. Weissman DE. Glucocorticoid treatment for brain metastases and epidural spinal cord compression: a review. J Clin Oncol 1988;6:543-51.

6. Diener-West M, Dobbins TW, Phillips TL, Nelson DF. Identification of an optimal subgroup for treatment evaluation of patients with brain metastases using RTOG study 7916. Int J Radiat Oncol Biol Phys 1989;16: 669-73.

7. Borgelt B, Gelber R, Kramer S, et al. The palliation of brain metastases: final results of the first two studies by the Radiation Therapy Oncology Group. Int J Radiat Oncol Biol Phys 1980;6:1-9.

8. Mehta MP, Rodrigus P, Terhaard $\mathrm{CH}$, et al. Survival and neurologic outcomes in a randomized trial of motexafin gadolinium and whole-brain radiation therapy in brain metastases. J Clin Oncol 2003;21:2529-36.
9. Eichler AF, Kahle KT, Wang DL, et al. EGFR mutation status and survival after diagnosis of brain metastasis in nonsmall cell lung cancer. Neuro Oncol 2010;12:1193-9.

10. Pao W, Miller V, Zakowski M, et al. EGF receptor gene mutations are common in lung cancers from "never smokers" and are associated with sensitivity of tumors to gefitinib and erlotinib. Proc Natl Acad Sci U S A 2004;101:13306-11.

11. Han SW, Kim TY, Hwang PG, et al. Predictive and prognostic impact of epidermal growth factor receptor mutation in non-small-cell lung cancer patients treated with gefitinib. J Clin Oncol 2005;23:2493-501.

12. Gow $\mathrm{CH}$, Chien $\mathrm{CR}$, Chang YL, et al. Radiotherapy in lung adenocarcinoma with brain metastases: effects of activating epidermal growth factor receptor mutations on clinical response. Clin Cancer Res 2008;14:162-8.

13. Lin JJ, Cardarella S, Lydon CA, et al. Five-year survival in EGFR-mutant metastatic lung adenocarcinoma treated with EGFR-TKIs. J Thorac Oncol 2016;11:556-65.

14. Italiano A, Vandenbos FB, Otto J, et al. Comparison of the epidermal growth factor receptor gene and protein in primary non-small-celllung cancer and metastatic sites: implications for treatment with EGFR-inhibitors. Ann Oncol 2006;17:981-5.

15. Kuukasjärvi T, Karhu R, Tanner M, et al. Genetic heterogeneity and clonal evolution underlying development of asynchronous metastasis in human breast cancer. Cancer Res 1997;57:1597-604.

16. Takahashi K, Kohno T, Matsumoto S, et al. Clonality and heterogeneity of pulmonary blastoma from the viewpoint of genetic alterations: a case report. Lung Cancer 2007;57:103-8.

17. Gallegos Ruiz MI, van Cruijsen H, Smit EF, et al. Genetic heterogeneity in patients with multiple neoplastic lung lesions: a report of three cases. J Thorac Oncol 2007;2:12-21.

18. Rao UN, Jones MW, Finkelstein SD. Genotypic analysis of primary and metastatic cutaneous melanoma. Cancer Genet Cytogenet 2003; 140:37-44.

19. Matsumoto S, Takahashi K, Iwakawa R, et al. Frequent EGFR mutations in brain metastases of lung adenocarcinoma. Int J Cancer 2006;119:1491-4.

20. Shin DY, Na II, Kim CH, Park S, Baek H, Yang SH. EGFR mutation and brain metastasis in pulmonary adenocarcinomas. J Thorac Oncol 2014;9:195-9.

21. Kalikaki A, Koutsopoulos A, Trypaki M, et al. Comparison of EGFR and K-RAS gene status between primary tumours and corresponding metastases in NSCLC. Br J Cancer 2008;99:923-9.

22. Luo D, Ye X, Hu Z, et al. EGFR mutation status and its impact on survival of Chinese non-small cell lung cancer patients with brain metastases. Tumour Biol 2014;35:2437-44. 